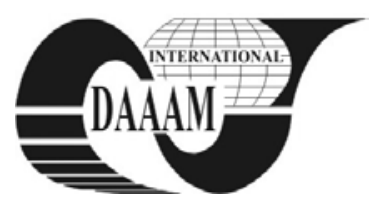

Annals of DAAAM for 2011 \& Proceedings of the 22nd International DAAAM Symposium, Volume 22, No. 1, ISSN $1726-9679$ ISBN 978-3-901509-83-4, Editor B. Katalinic, Published by DAAAM International, Vienna, Austria, EU, 2011 Make Harmony between Technology and Nature, and Your Mind will Fly Free as a Bird

\title{
MODULAR SYSTEM FOR MICROPROCESSOR APPLICATIONS
}

\author{
BRAZDA, M[ichal]; NECKAR, P[avel] \& ADAMEK, M[ilan]
}

\begin{abstract}
For the developing microprocessor applications are often used development boards. In many cases, are these boards designed for only one type of microprocessor with unchangeable structure of the connecting peripherals. The aim of this work is creation of new modular system for developing application. The modular system can be used for any type of microprocessor also for different connection of peripheral devices and for creating better microprocessors applications. Key words: microprocessor, development, board, modular, $P C B$
\end{abstract}

\section{INTRODUCTION}

Many types of development boards which are used by the developers have problem with modularity, because they have only one type of the development board for specific type of microprocessor. These boards have limitation of peripheral connections which are without possibility of change (port of connection).

The modular system for programming any types of microprocessor is developed on Faculty of Applied Informatics. The system can offer a new approach for creation applications which are based on Freescale Semiconductor chips. The project solved the problem with programming more than one type of MCU via modular system.

\section{INTRODUCTION TO THE DEVELOPMENT BOARDS}

The reason for creating developed boards came from question: "How to provide learning of new microprocessors for specific operations". The other reason was based on school subjects like Informatics and Assembler programming. The first development board was 8085 microprocessor training unit from Paccom. After first microprocessor training unit the history shows big progress in this part of industry.

A microprocessor development board is a printed circuit board containing a microprocessor and the minimal support logic.

Typically the development boards used following component:

- Clock

- Voltage regulator

- Reset button

- Communications chip

- Switches

- Led's

- Prototyping area

- Chip connections

The most important feature of the microprocessor development board is the ROM memory (Flash) based on builtin machine language monitor, or "debugger" as it was also sometimes called.

\section{PERIPHERAL DEVICES FOR MODULAR DEVELOPMENT BOARD}

Specific property of new modular development board was established on function of fully removable peripheral parts for changing their placement. Modular development board contains connectors for communication between peripheral devices and microprocessor board.

For testing correct function were designed several peripheral modules:

- $\quad$ LED module - contains eight red color diodes and support circuits.

- Switch module - contain eight buttons which are connected to the ground.

- Matrix keyboard - contain sixteen buttons connected into the four rows and four columns.

- 7-segment display - contains eight digits which are controlled by the time period from processor clock output.

- Matrix display (24x7) - the display is composed from two PCBs. First PCB is used only for controlling and the second one is used for displaying required data.

Main removable parts:

- PCB with microprocessor - which provides connection between microprocessor, peripherals and programmer.

- Power supply board - is designed for energy supplying to the microprocessor and his peripheral devices.

- Programmer board - it is based on the OSBDM (open source programmer which was created by Freescale). This programmer can be used for programming microprocessors with HCS08 (8bits) and ColdFire V1 (32 bits) core.

\section{REDUCTION FOR MICROPROCESSOR}

One of the reasons for creating reductions for microprocessors was giving the opportunity to create own system for programming chips without requirement of completely new developed board for any different microprocessor. The reduction for microprocessor is easily designed than creation of all new system.

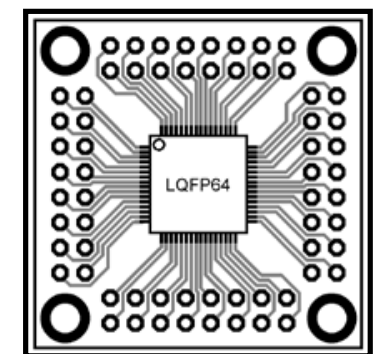

Fig. 1. Processor board 


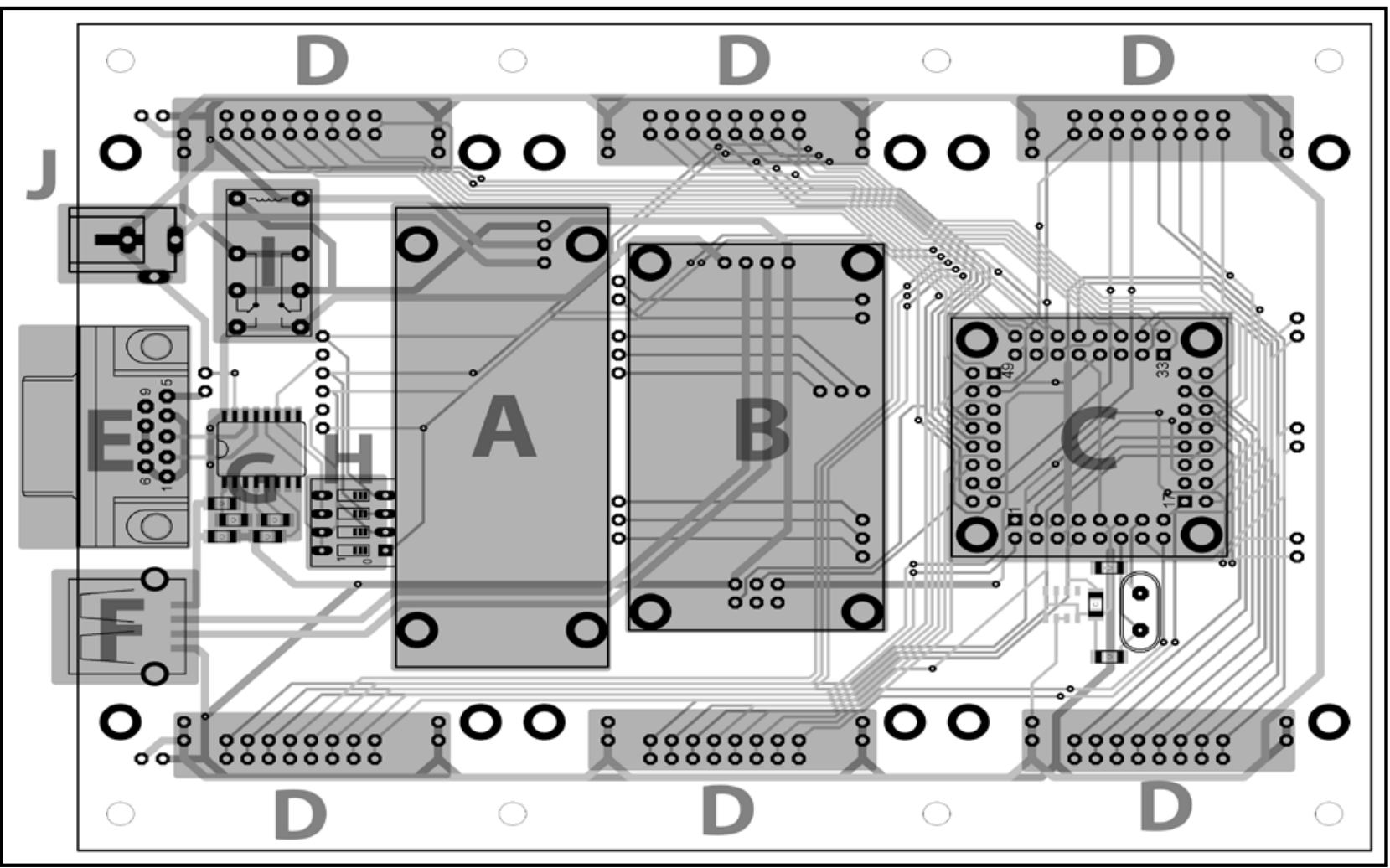

Fig.2 Development board

Fig. 1. shows one of created applicable reduction for microcontrollers MC9S08QE128 (8-bit HCS08 core) and MCF51QE128 (32-bit Cold-Fire V1 core).

\section{DESCRIPTION OF MODULAR SYSTEM FOR MICROPROCESSOR APPLICATIONS}

For better understanding is placed a Fig. 2. in this chapter. Each blocks on Fig. 2. has a capital letter which is described below.

A External power supply board - is used only for power supplying of peripherals. It is used only when USB power supplying is not enough for correct function of development board and external power source is plugged.

B Programmer board

C Microprocessor board - Reduction board

D Peripherals connection connectors

E CANNON 9 connector for RS-232 communication

F USB connector

G RS-232 receiver / transceiver with external parts

H Select switch for RS-232 channels

I Power supply switching relay

J External power source connector

\section{PROGRAMATOR BOARD}

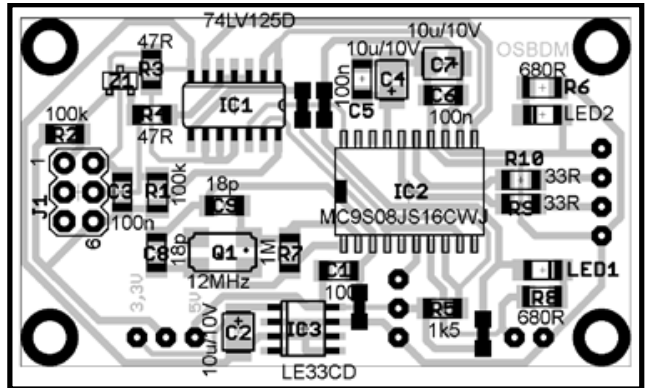

Fig 3. Programmer board
Heart of this board is microcontroller MC9S08JS16 (IC2). This controller provide link through the USB between PC and processor which is connected on the development board. Programmer board is also used for powering microprocessor board. Power supply which is including on this board can be changed from 3,3V to $5 \mathrm{~V}$ (it depends on the requirements of the processor).

\section{CONCLUSION}

The new type of modular system for microprocessor applications was built only for possibility to connect other microprocessors with complete independence on their diversity. In future will be prepared new Reduction boards for these microprocessor types: MC9S08GB60, MC9S08AC32 and MCF51AC128. As well as the development of new reduction boards will be prepared, the new peripheral devices are preparing in this moment for laboratory where the students learn about the technology of microprocessor applications.

\section{ACKNOWLEDGEMENTS}

This paper is supported by the Internal Grant Agency at TBU in Zlin, projects No. IGA/46/FAI/11/D, IGA/47/FAI/10/D and by the European Regional Development Fund under the project CEBIA-Tech No. CZ.1.05/2.1.00/03.0089.

\section{REFERENCES}

Hardware 8888. 1. 11.7.2009 [ref. 2011-10-01].Microprocessor development board. : www.hardware8888.supersized.org

MCF51QE128 Reference Manual. Freescale Semiconductor. 09/2007, Rev. 3, [ref. 2011-10-01]. www.freescale.com

MC9S08QE128 Reference Manual. Freescale Semiconductor. 06/2007, Rev. 2, [ref. 2011-10-01]. www.freescale.com

OSBDM-JM60: Open Source BDM for HCS08/RS08. Freescale Semiconductor. 11.5.2009, version 2, [ref. 201110-01]. www.freescale.com

LM117/217. STMicroelectronics. 2003, version 1, [ref. 201110-01]. www.st.com, Printed in Italy 